\title{
How are Love, Loneliness, and Health Related?
}

\author{
Ami Rokach* \\ Department of pyschology, York University, Canada \\ *Corresponding author: Ami Rokach, Department of pyschology, York University, Toronto, Canada, Tel: (416)736-5117; Email: arokach@yorku.ca
}

Submission: 監June 27, 2018; Published: 眥 September 26, 2018

\begin{abstract}
Love and loneliness are not thought of as relating to each other, but under some circumstances, they do. This article reviews the concepts of intimacy and love. It explores what each of these concepts are, and the positive effects that love has on us psychologically, emotionally and physically. We describe what happens when love wanes, the impact it has on our romantic union, what are the causes for its disappearance and how loneliness may, thus, become an integral part of the relationship.
\end{abstract}

Keywords: Intimacy; Love; Romantic union; Love busters; Loneliness

\section{Introduction}

\section{How are love, loneliness and health related?}

People are social animals, and as such they need to belong, to be part of an intimate, lasting, caring relationship with a partner who is close and deeply concerned about them [1]. To fulfil our need for closeness, we aim to establish close contact with others and become part of intimate relationships. It has been shown that people live happier, longer, healthier, and more fulfilling lives when they are closely connected to others [2].

\section{How does love to affect us?}

Love relationships are the epitome of closeness and intimacy. Feelings of intimacy can emerge in any social interactions, and progress to emotional and physical intimacy [3]. A salient component of intimacy is the extent to which people believe that interaction partners understand, validate, and care for them [4]. That responsiveness provides the person who is on the receiving end with validation of the self, which lead to feelings of acceptance, belonging, and trust which contribute to emotional and physical wellbeing, since Intimacy, and love, appear to decrease physical symptoms of illness and contribute to our vitality $[5,6]$. Newlyweds who were observed during lab interactions, were more satisfied with their marriage, if during those interactions they expressed love and affection [7]. Studies employing brain imaging confirmed that acceptance, intimacy, and romantic love are associated with neural activity that has implications for health [8]. And so, being accepted [vs. rejected] by a potential romantic partner increases activation in opioid receptors related to reward, analgesia, and positive affect [9]. Another study which measured brain activity during viewing people's romantic partners, indicated activation in those regions related to attachment and reward [involving dopamine, and vasopressin receptors], and with regions that are involved in pain and mood regulation [10]. It was also found that thinking about one's romantic partner, increases blood glucose levels [11]. Physical touch and intimacy can positively influence our health. Romantic partners had lower cortisol levels on days with higher physical intimacy [holding hands, hugging], and when people experienced increase in intimacy, they experienced decrease in somatic symptoms [12].

\section{The nature of intimacy}

Intimacy is composed of knowledge, caring, interdependence, mutuality, trust, and commitment [13]. Intimate partners' lives are intertwined, and they affect each other continually, impacting meaningfully each other in many areas of life, in various ways, and over long periods of time [10]. The hallmark of an intimate relationship is that its partners have extensive personal, confidential, and private knowledge about each other. That information may include the partners' histories, preferences, feelings, and desires that they would commonly not reveal to other people. Intimate partners, naturally, care about each other and feel affectionate towards their partner than they would to others. In the behaviour of intimate couples, we can often observe mutuality, thinking of themselves as a unit ["us"] and seeing themselves as overlapping in various respects [14]. Trust is a main component of intimacy, where the partners know that it is safe to open and that their partner will be there to support and respond to their needs [15]. Finally, intimate partners expect the relationship to endure for many years, are committed to their relationship, and consequently invest time, effort, and the resources at their disposal.

Does love to endure? While many complain, after years of togetherness, that "love went out the window," there are other couples whose love continues even 10 or 20 years into their 
relationship or marriage. People who were studied, demonstrated that when they people see a picture of their loved one, they experience activation of the reward centres in their brains just as they did when they were falling in love years earlier [16]. While it seems that passion may decline over time, intimacy and commitment increase with age. It has been observed that compassionate love is more stable than romantic love [17].

Historically, women depended on their husbands for status and economic well-being, so their emotional yearnings had to be controlled to please the man who came from a higher social background and had a good financial potential. Men, on the other hand, did not need to engage in all those "calculations" and were able to marry a woman which they passionately loved. That resulted in, women who passively waited for the right match, while men were free to initiate a relationship with those they loved [18] We now entered the 21st century, when women depend less on marriage for status and financial well-being, an era when they can pursue education and career opportunities, and thus they seek men to whom they are attracted, rather for purposes of financial gains [19]. In the Western culture currently, both genders insist on a "love match" regardless of the practical implications or potential [20].

\section{On love}

Love is elusive and almost impossible to define, or 'pin down'. Love may be confused with lust and infatuation [21]. Writers, philosophers, poets, and sculptors-to name a few-have attempted to describe and capture the meaning of love for centuries, but it is only recently that social scientists have shown interest in researching and writing about love [22]. To begin to understand love, we can shed light on what happens to us biologically when we fall in love. One of the structures involved in falling in love is the limbic system, which includes the basal nuclei, the thalamus, and the hypothalamus. The hypothalamus is directly involved in both behavioural and sexual function. Combining these two important functions, clarifies the importance of the limbic system to falling in love. Research has found that desire felt, causes a person to respond with their entire body. As stated earlier, when one is around an object of their desire, adrenaline -or epinephrine - is released, from the adrenal medulla. That reaction causes the person's heart rate to increase, the pupils become dilated, the sweat glands are stimulated, and the brain becomes increasingly more alert. This reaction is exactly how people describe the feeling and energy of being "in love" [23].

How love is expressed and experienced may be influenced by gender [24]. observed that not much research was conducted on the important saying "I Love You", despite it commonly being the decisive moment for the advancement of romantic relationship. With respect to the expression of love, even though these three small words "I love you," appear to be a critical delineation in relationship, not much research was devoted to understanding the process [25]. That may not be so surprising, since women and men differ in their expression of emotions and in their descriptions of related cognitions Barbara, 2008. Interestingly, women appear to enjoy a neurological advantage in terms of processing multisensory, emotional experiences [26]. That may explain why women are faster at perceiving others' emotions and have more confidence than do men when expressing affection, liking, and love to the opposite sex $[27,28]$. This view may also explain the intimacy, parenting, and relationship problems that men, who are 'inexpressive and restrictive emotionally' [27] often complain about [29]. Observing how the genders respond to love, [30] pointed out that "both sexes reported a desire to have sex at the same time they were certain of their own and their partner's feelings. This suggests that women, relative to men, are making more careful assessments of their partners before committing sexually and emotionally to a relationship. Interestingly, other than the above, our data indicated no significant differences between the sexes, revealing that women's general viewpoints [including cynical beliefs, e.g., "Love is a waste of time"] about love, dating, and romance, are not different than those of men. The research cited demonstrates that women are not greater fools for love than are men [as is the common societal stereotype]. In fact, the data arguably show that both sexes are equally as pragmatic and as foolish about love.

\section{The universality of love}

Scans of the brains of people who reported that they were in love at the time, involving fMRI [magnetic resonance], demonstrated that the experience of romantic love has been correlated with the deactivation of brain centres responsible for critically assessing others and for making moral judgments. Based on such research it was asserted that [1] love is blind, and thus, when in love, we tend to overlook the loved one's follies [31], and that love is most probably universal and is part of human nature; thus, it can be traced to our neural connections [32,33]. confirmed the notion that love is universal, and that man and women have the capacity to feel love, regardless of his culture, gender, or age. One example of its universality can be found, in the nineteenth century's attempt by the Oneida society, to banish romantic love since they believed that it was but a deceit, covering up for sexual lust. Another example is that of the Shakers who sought to banish love since they saw it as undignified and a threat to the larger society. The Mormons, in the nineteenth century, viewed love as a disruption in one's life and sought to eliminate it. Not surprisingly, despite all that, romantic love persisted and flourished, hidden from the harsh eyes of the group's elders. It appears that love can be fuelled by others' attempts to deny or suppress it. "Lovers have no choice; they can quell their feelings temporarily, or muffle the expression, but they cannot excise them entirely" [33]. The same thing happens in cultures that impose arranged marriages and permit polygamy [10].

While love is universal, however, its expression may not be, and is expressed in a culturally acceptable manner. Love itself is said to be experienced identically in the U.S. and say, in China [34], while romantic and compassionate love are recognized as distinctly unique across cultures with some interesting cultural nuances [35]. Chinese people describe their partner's desired personality, their opinions, and their own physical arousal when addressing their feelings of love [36]. And on the other hand, Americans when describe falling in love, seem to emphasize the similarities 
between themselves and their partner, and possibly, the latter's good looks. Romantic fantasies-which colour love in warm, cosy tones with the hope that it will last forever-are more common in America, while the Chinese tend to view it in less cosy tones [37]. Another interesting observation is that the requirement of love as necessity for marriage is much more pronounced in the Western, individualistic, countries than in the East. College students in China are commonly guided by their parents when they seek a partner to marry, whereas in America the choice of a future spouse is seen as the choice of the one who will marry him [38].

\section{Love, health and loneliness: when trouble starts}

Marriage is commonly associated with decrease in loneliness. Marriage has been known to be one of the strongest protective factors against loneliness, in general, and for older adults and is quite common in marriages [39-41]. However, Stack [1988] found that intervening factors such as financial security, health and companionship may exacerbate loneliness in intimate relationships. Loneliness may set in due to the incongruence in marital expectations and needs of the couple. It was] found that increased dyadic cohesion [or intimacy and communication] are associated with decreased loneliness, thus highlighting the importance of intimacy and communication in intimate unions. It suggests that loneliness in marriage is alleviated by time spent together and open and honest communication, which if not present seem to exacerbate loneliness [42].

Marital quality may determine whether the relationship which we are part of protects against or fosters loneliness, especially in later life [43]. Marriage was found to have protective psychological, emotional and physical health benefits, partly because of married couples' greater access to economic and social resources [44-46]. However, the benefits of marriage are heavily dependent on the quality of the couple's relationship and may be both supportive or/and straining [47-49] observed in relation to what can spoil a marriage, that "insensitive behaviour and an unsatisfying sex life with a spouse are related with increased loneliness for married persons, whereas greater marital support and lower marital strain are both related with reduced loneliness" [50]. When examining the interaction of gender and marital quality, married women are more influenced by marital quality than their husbands [51]. Interestingly, women are both more likely to spread their loneliness to others and to be influenced by the loneliness of their social partners than men are [52].

Romantic relationships have been found to influence physical health, and even play a role in CHD [Coronary heart disease] [53]. Being married or involved in an intimate relationship has been shown to reduce the risk for developing CHD [54]. Those relationships are important for our physical health, not just for their presence, but mainly for their quality [55]. Biologic and behavioural risk factors for CHD are key targets in preventing and treating the disease. Smoking, hypertension, elevated blood lipids and glucose, dietary fat and caloric intake, as well as inactivity have been identified and studied. In addition, lets highlight the psychosocial factors and their contribution to cardiac problems. The following features predict the development and progression of CHD: qualities of personal relationships, features of social environments, and aspects of emotional adjustment and personality [56]. Intimate relationships which are not good, close and supportive, are a central element of psychosocial risk for CHD [57].

Characteristics of intimate relationships, personality, and emotional adjustment can contribute to CHD through behaviours [e.g., smoking, physical activity], or lack of them in case of positive effects of intimate relations. Disruption of marriage and intimate relations, and divorce may lead to mortality [58], and/or to coronary atherosclerosis, and reduced survival in CHD [59,60]. Greater conflict, worries, and demands in cohabiting relationships [i.e., married and non-married couples] predict incident CHD [61], severity of atherosclerosis $[62,63]$, and poor clinical outcomes [e.g., recurrent coronary events, reduced survival] in CHD patients $[64,65]$.

To conclude, one partner's behaviour influences the internal experiences and overt actions of the other, with corresponding effects on the latter partner's physiology [53]. For example, criticism and blame from a partner are typically experienced quite negatively, evoking defensive, angry, and quarrelsome responses, and increased physiological reactivity. In contrast, a partner's affection and warm support are experienced positively, evoking expression of warmth in return and reductions in unhealthy physiological responses and increases in protective physiological patterns.

\section{References}

1. Miller RS (2012) Intimate relationships ( $6^{\text {th }}$ edn), McGraw Hill, New York, USA.

1. Koball Hl, Moiduddin E, Henderson J, Goesling B, Besculides M (2010) What do we know about the link between marriage and health. Journal of Family Issues 31(8): 1019-1040.

2. Pietromonaco PR, Collins NL (2017) Interpersonal mechanisms linking close relationships to health. Am Psychol 72(6): 531-542.

3. Laurenceau JP, Barrett LF, Pietromonaco PR (1998) Intimacy as an interpersonal process: The importance of self-disclosure, partner disclosure, and perceived partner responsiveness in interpersonal exchanges. J Pers Soc Psychol 74(5): 1238-1251.

4. Kane HS, Slatcher RB, Reynolds BM, Repetti RL, Robles TF (2014) Daily self-disclosure and sleep in couples. Health Psychol 33(8): 813-822.

5. Lun J, Kesebir S, Oishi S (2008) On feeling understood and feeling well: The role of interdependence. J Res Pers 42(6): 1623-1628.

6. Graber EC, Laurenceau JP, Miga E, Chango J, Coan I (2011) Conflict and love: Predicting newlywed marital outcomes from two interaction contexts. J Fam Psychol 25: 541-550.

7. Morelli SA, Torre JB, Eisenberger NI (2014) The neural bases of feeling understood and not understood. Soc Cogn Affec Neurosci 9(12): 18901896.

8. Hsu DT, Sanford BJ, Meyers KK, Love TM, Hazlett KE, et al. (2013) Response of the $\mu$-opioid system to social rejection and acceptance. Molecular Psychiatry 18(11): 1211-1217.

9. Acevedo BP, Aron A, Fisher HE, Brown LL (2012) Neural correlates of long-term intense romantic love. Soc Cogn Affect Neurosci 7(2): 145159. 
10. Stanton SC, Campbell L, Loving TJ (2014) Energized by love: Thinking about romantic relationships increases positive affect and blood glucose levels. Psychophysiology 51(10): 990-995.

11. Stadler G, Snyder KA, Horn AB, Shrout PE, Bolger NP (2012) Close relationships and health in daily life: A review and empirical data on intimacy and somatic symptoms. Psychosom Med 74(4): 398-409.

12. Ben Ari A, Lavee Y (2007) Dyadic closeness in marriage: From the inside story to a conceptual model. Journal of Social and Personal Relationships 24(5): 627-644.

13. Fitzsimons GM, Kay AC (2004) Language and interpersonal cognition: Causal effects of variations in pronoun usage on perceptions of closeness. Personality and Social Psychology Bulletin 30(5): 547-557.

14. Reis HT, Clark MS, Holmes JG (2004) Perceived partner responsiveness as an organizing construct in the study of intimacy and closeness. In: Mashek DJ, Aron A (Eds.), Handbook of Closeness and Intimacy, Mahwah, USA, pp. 201-225.

15. Sprecher S, Regan PC (1998) Passionate and compassionate love in courting and young married couples. Sociological Inquiry 68(2): 163185.

16. Safilios Rothschild C (1977) Love, sex and sex roles. Prentice Hall, Spectrum Books, NJ, USA.

17. Peplau LA (2002) Roles and Gender. In: Kelley HH, Berscheid E, Christensen A (Eds.), Close relationships, Percheron Press, NY, USA, pp. 20-260.

18. Allgeier ER, Weiderman MW (1991) Love and mate selection in the 1990s. Free Inquiry 11(3): 25-27.

19. Knox D, Schacht C (2010) Choices in relationships: An introduction to marriage and the family ( $10^{\text {th }}$ edn), Belmont, Wadsworth, CA, USA.

20. Fehr B (2006) A prototype approach to studying love. In: Sternberg RJ, Weis K (Eds), The new psychology of love, Yale University Press. New Haven, USA, pp. 225-246.

21. Chapman, Heather M (2011) Love: A Biological, Psychological and Philosophical Study. Senior Honors Projects, USA, p. 254.

22. Harrison MA, Shortall JC (2011) Women and men in love: Who really feels it and says it first? The J Soc Psychol 151(6): 727-736.

23. Baxter L, Braithewaite D (2008) Engaging theories in interpersonal communication: Multiple perspectives. Thousand Oaks, Sage, USA.

24. Collignon O, Girard S, Gosselin F, Saint Amour D, Lepore F, et al. (2010) Women process multisensory emotion expressions more efficiently than men. Neuropsychologia 48(1): 220-2140.

25. Blier M, Blier Wilson L (1989) Gender differences in self-rated emotional expressiveness. Sex Roles 21(3-4): 287-295.

26. Hampson E, van Anders S, Mullin L (2006) A female advantage in the recognition of emotional facial expressions: Test of an evolutionary hypothesis. Evolution and Human Behavior 27(6): 401-416.

27. Balswick J (1988) The inexpressive male. Lexington Books, Lexington, MA, USA.

28. Fisher HE, Aron A (2002) Defining the brain systems of lust, romantic attraction and attachment. Arch sex behaves 31(5): 413-419.

29. Fisher H (2004) Why we love: The nature and chemistry of romantic love. Henry Holt, NY, USA.

30. Buss DM (2006) The evolutionary genetics of personality: Doesmutation load signal relationship load. Behavioral and Brain Sciences 29(4): 409.

31. Xu X, Aron A, Brown L, Cao G, Feng T, et al. (2011) Reward and motivation systems: A brain mapping study of early-stage intense romantic love in Chinese participants. Human Brain Mapping 32(2): 249-257.

32. Shaver PR, Murdaya U, Farley RC (2001) Structure of the Indonesian emotion lexicon. Asian Journal of Social Psychology 4(3): 201-224.
33. Riela S, Rodriguez G, Aron A, Xu X, Acevedo BP (2010) Experiences of falling in love: Investigating cultural, ethnicity, gender, and speed. Journal of Social and Personal Relationships 27(4): 473-493.

34. Jackson T, Chen H, Guo C, Gao X (2006) Stories we love by: Conceptions of love among couples from the people's republic of China and the United States. Journal of Cross-Cultural Psychology 37(4): 446-464.

35. Zhang S, Kline SL (2009) Can I make my own decision? A cross-cultural study of perceived social network influence in mate selection. Journal of Cross-Cultural Psychology 40(1): 3-23.

36. Fokkema T, de Jong Gierveld J, Dykstra PA (2012) Cross-national differences in older adult loneliness. J Psychol 146(1): 201-228.

37. Perissinotto CM, Cenzer IS, Covinsky KE (2012) Loneliness in older persons: A predictor of functional decline and death. Arch Intern Med 172(14): 1078-1083.

38. Sundstrom G, Fransson E, Malmberg B, Davey A (2009) Loneliness among older Europeans. European Journal of Ageing 6(4): 267-275.

39. Ayalon L, Shiovitz S, Palgi Y (2013) Associations of loneliness in older married men and women. Aging Ment Health 17(1): 33-39.

40. Balswick J (1988) The inexpressive male. Lexington, MA: Lexington Books, Kentucky, US.

41. Carr D, Springer KW (2010) Advances in families and health research in the $21^{\text {st }}$ century. Journal of Marriage and Family 72(3): 743-761.

42. Di Matteo MR (2004) Social support and patient adherence to medical treatment: A meta-analysis. Health Psychol 23(2): 207-218.

43. Berscheid E (2006) Seasons of the heart. Dynamics of romantic love: Attachment, caregiving and sex. In: Mikulincer M, Goodman GS (Eds.), Guilford Press, USA.

44. Hawkins DN, Booth A (2005) Unhappily ever after: Effects of long-term, low-quality marriages on well-being. Social Forces, 84(1): 451-471.

45. Walen HR, Lachman ME (2000) Social support and strain from partner, family, and friends: costs and benefits for men and women in adulthood. Journal of Social and Personal Relationships 17(1): 5-30.

46. Stokes JE (2017) Marital quality and loneliness in later life: A dyadic analysis of older married couples in Ireland. Journal of Social and Personal Relationships 34(1): 114-135.

47. Chen Y, Feeley TH (2014) Social support, social strain, loneliness and well-being among older adults: An analysis of the health and retirement study. Journal of Social and Personal Relationships 31(2): 141-161.

48. Proulx CM, Helms HM, Buehler C (2007) Marital quality and personal well-being: A meta-analysis. Journal of Marriage and Family 69(3): 576593.

49. Cacioppo JT, Fowler JH, Christakis NA (2009) Alone in the crowd: The structure and spread of loneliness in a large social network. J Pers Soc Psychol 97(6): 977-991.

50. Smith TW, Baucom BRW (2017) Intimate relationships, individual adjustment and coronary heart disease: Implications of overlapping associations in psychosocial risk. American Psychologist 72(6): 578589.

51. Floud S, Balkwill A, Canoy D, Wright FL, Reeves GK, et al. (2014) The million women study collaborators. marital status and ischemic heart disease incidence and mortality in women: A large prospective study. BMC Med 12: 12-42.

52. Robles TF, Slatcher RB, Trombello JM, McGinn MM (2014) Marital quality and health: A meta-analytic review. Psychological Bulletin 140(1): 140-187.

53. Steptoe A, Kivimäki M (2013) Stress and cardiovascular disease: An update on current knowledge. Annual Review of Public Health 34: 337354. 
54. Malouff JM, Thorsteinsson EB, Schutte NS, Bhullar N, Rooke SE (2010) The five-factor model of personality and relationship. Journal of Research in Personality 44(1): 124-127.

55. Sbarra DA, Law RW, Portley RM (2011) Divorce and death: A metaanalysis and research agenda for clinical, social, and health psychology. Perspect Psychol Sci 6(5): 454-474.

56. Dupre ME, Nelson A (2016) Marital history and survival after a heart attack. Soc Sci Med 170: 114-123.

57. Kilpi F, Konttinen H, Silventoinen K, Martikainen P (2015) Living arrangements as determinants of myocardial infarction incidence and survival: A prospective register study of over 300,000 Finnish men and women. Soc Sci Med 133: 93-100.

58. Lund R, Rod NH, Thielen K, Nilsson CJ, Christensen U (2014) Negative aspects of close social relations and 10-year incident ischaemic heart disease hospitalization among middle-aged Danes. European Journal of Preventive Cardiology 21(10): 1249-1256.
59. Gallo LC, Troxel WM, Kuller LH, Sutton TK, Edmundowicz D, et al. (2003) Marital status, marital quality, and atherosclerotic burden in postmenopausal women. Psychosom Med 65(6): 952-962.

60. Joseph NT, Kamarck TW, Muldoon MF, Manuck SB (2014) Daily marital interaction quality and carotid artery intima-medial thickness in healthy middle-aged adults. Psychosom Med 76(5): 347-354.

61. King KB, Reis HT (2012) Marriage and long-term survival after coronary artery bypass grafting. Health Psychol 31(1): 55-62.

62. Goldman N (2001) Social inequalities in health disentangling the underlying mechanisms. Ann N Y Acad Sci 954: 118-139.

63. Idler EL, Boulifard DA, Contrada RJ (2012) Mending broken hearts: Marriage and survival following cardiac surgery. J Health Soc Behav 53(1): 33-49.

64. Sprecher S, Regan PC (1998) Passionate and compassionate love in courting and young married couples. Sociological Inquiry 68(2): 163185.
Creative Commons Attribution 4.0 International License

For possible submissions Click Here
Submit Article

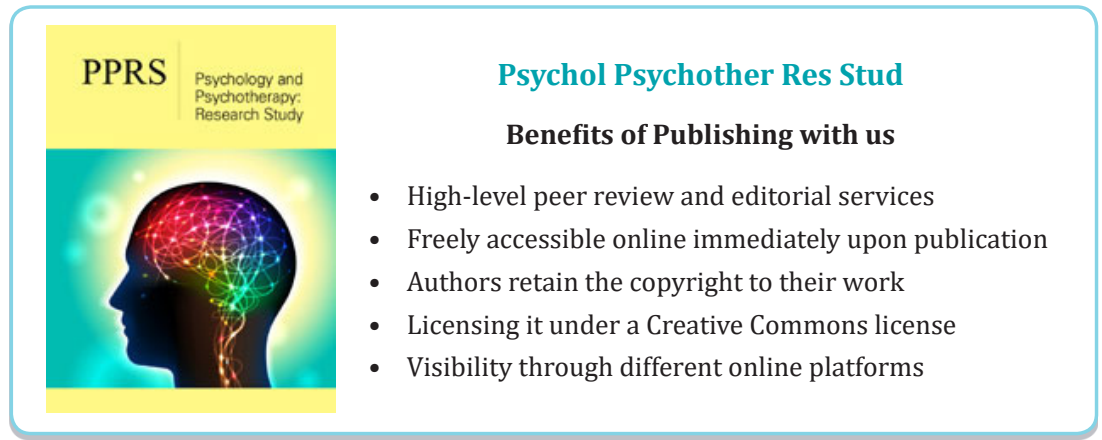

